\title{
Análise do impacto de fatos relevantes no retorno das ações de empresa de educação superior
}

A pesquisa propõe analisar o impacto de fatos relevantes dos dois últimos anos nos preços das ações da Kroton Educacional S.A., empresa do setor de educação de ensino superior. As reações dos investidores diante das informações que normalmente alteram decisões gerenciais das instituições podem influenciar no retorno das ações. A pesquisa trará à luz como foi o desempenho das ações da empresa diante de vários fatos relevantes e que podem ter impactado os resultados contábeis e financeiros da empresa. Ademais, verificará se a estratégia de fusão foi uma ação de gestão eficaz para manter o negócio atrativo e rentável diante da crise vivida pelo país. Por meio de uma pesquisa de natureza empírico-analítica, exploratória, de abordagem quantitativa, e sob a forma de estudo de caso, utilizase o estudo de eventos para avaliar se os preços e retornos das ações foram alterados após as seguintes divulgações: (i) resultado do ano de 2015 em meio à crise econômica; (ii) alteração das regras de concessão do Fundo de Financiamento ao Estudante do Ensino Superior (FIES); e (iii) compras e fusões das empresas deste setor e a publicação de uma revista criticando o programa de crédito estudantil FIES. A janela de evento utilizada foi de 4 dias antes (D-4) até 4 dias depois (D+4) ao redor da data do evento (D0), com uma janela de estimação de 40 dias (D-5 a D-44). Para o cálculo do beta utilizou-se o método dos mínimos quadrados e estimou-se a partir daí os retornos anormais e os retornos anormais acumulados. O retorno anormal foi calculado a partir do modelo de mercado. Obteve-se a ocorrência de p-value inferior a 5\%, que comprova a forma de eficiência semiforte de mercado nos resultados, visto que os preços das ações foram impactados, porém logo após voltaram ao seu patamar normal, pois o mercado havia absorvido a informação.

\section{Analysis of the impact of relevant facts on the return of higher education company shares}

\begin{abstract}
The research proposes to analyze the impact of relevant facts of the last two years on the share prices of Kroton Educacional S.A., a company in the higher education sector. Investors' reactions to information that normally alter managerial decisions of institutions can influence share returns. The research will bring to light how the company's performance in the face of several relevant facts and that may have impacted the accounting and financial results of the company. In addition, it will verify if the merger strategy was an effective management action to keep the business attractive and profitable in the face of the crisis experienced by the country. An empirical-analytical, exploratory, quantitative-based and case-study research is used to evaluate whether the prices and stock returns were changed after the following disclosures: (i) result of the year 2015 amid the economic crisis; (ii) alteration of the rules for granting the Financing Fund for Higher Education Students; and (iii) purchases and mergers of companies in this sector and the publication of a magazine criticizing the Financing Fund for Higher Education Students. The event window used was 4 days before (D-4) until 4 days later $(D+4)$ around the event date (D0), with a 40 -day estimation window (D-5 to $D-44)$. The least squares method was used to calculate the beta and the abnormal returns and accumulated abnormal returns were estimated. The abnormal return was calculated from the market model. A p-value of less than $5 \%$ was obtained, which demonstrates the form of semiforteed market efficiency in the results, since stock prices were impacted, but soon after they returned to their normal level, since the market had absorbed the information.
\end{abstract}

Keywords: Abnormal Retuns; Event Study Analysis; Informacional Efficiency.

\section{Topic: Finanças Empresariais}

Reviewed anonymously in the process of blind peer.

Daniele Santos Damascena

Pontifícia Universidade Católica de São Paulo, Brasil

http://lattes.cnpq.br/0149827126337111

daniele_damascena@yahoo.com.br

\section{Sandra Egydio Pereira da Silva}

Pontifícia Universidade Católica de São Paulo, Brasil

http://lattes.cnpq.br/0399882904908894

sandra.egysil@gmail.com

\section{José Odálio dos Santos}

Pontifícia Universidade Católica de São Paulo, Brasil http://lattes.cnpq.br/7018280423685826

j.odalio@pucsp.br
Received: 03/10/2017

Approved: 03/12/2017

Alexandre Franco de Godoi (ic)

Pontifícia Universidade Católica de São Paulo, Brasil

http://lattes.cnpq.br/4704578926015219

http://orcid.org/0000-0002-4879-8520

godoi franco@hotmail.com
Referencing this:

DAMASCENA, D. S.; SILVA, S. E. P.; SANTOS, J. O.; GODOI, A. F.. Análise do impacto de fatos relevantes no retorno das ações de empresa de educação superior. Revista Brasileira de Administração Científica, v.8, n.3, p.1-12, 2017. DOI: http://doi.org/10.6008/SPC2179$\underline{684 X .2017 .003 .0001}$ 


\section{INTRODUÇÃO}

A partir de 2014, o Brasil entrou em recessão devido a problemas políticos e econômicos, culminando nas investigações sobre corrupção no país, na denominada 'Operação Lava Jato', que envolveram a Petrobrás e algumas das maiores construtoras do país. Estes fatores prejudicaram os cofres do governo e, em decorrência disto, muitas empresas diminuíram suas receitas, tendo que reduzir seus custos e promovendo a demissão de funcionários.

Segundo o IBGE (2017) a quantidade aproximada de desocupação no Brasil ao final do trimestre de julho a agosto 2017 era de 13,1 milhões de pessoas desocupadas, resultado este que, embora tenha apresentado leve recuo em relação ao trimestre de janeiro a março de 2017, quando alcançou aproximadamente 14,1 milhões de pessoas desocupadas, ainda assim continua sendo um dos maiores níveis de desocupação registrados se comparado com séries históricas de anos anteriores a partir de 2012.

Como consequência disso, um dos setores que tem sido severamente afetado é o da educação. Muitos alunos que arcavam com as mensalidades foram demitidos de seus empregos e deixaram seus estudos por não poderem pagar as mensalidades acadêmicas, diminuindo assim as receitas das faculdades. Ademais, outro fator que contribuiu para a redução de alunos no ensino superior privado está relacionado ao crédito do Fundo de Financiamento Estudantil (FIES).

A concessão deste tipo de crédito que até o final de 2014 era facilitada, a partir de 2015, por meio da Portaria Normativa no21 de 2014 do Fundo Nacional de Desenvolvimento da Educação - FNDE (2014), autarquia federal responsável pela execução de políticas educacionais do Ministério da Educação (MEC), passou-se a exigir uma pontuação mínima no Exame Nacional do Ensino Médio (ENEM), sendo definindo regras específicas para quem usa o financiamento simultaneamente à bolsa do Programa Universidade para Todos (ProUni).

Em decorrência da crise econômica e, consequentemente, da perda de postos de trabalho, aliada a maiores dificuldades para obtenção do crédito estudantil (FIES), parte dos alunos e candidatos as vagas desistiram da continuidade e ingresso no ensino privado superior. Assim, diante dos aspectos abordados o problema de pesquisa proposto para esta investigação empírica, procura obter respostas ao seguinte questionamento: Os eventos sistêmicos e eventos relacionados a estratégias de empresa afetaram, de forma estatisticamente significativa, o comportamento do retorno das ações ordinárias de uma das maiores empresas do setor de educação com ações negociadas na B3 - Brasil Bolsa Balcão?.

Por meio de uma pesquisa de natureza empírico-analítica, exploratória, de abordagem quantitativa, e sob a forma de estudo de caso, o objetivo da pesquisa é verificar se o desempenho das ações da Kroton Educacional S.A., uma das maiores empresas do setor de educação com ações negociadas na B3 - Brasil Bolsa Balcão foi afetado pelos eventos sistêmicos mencionados, bem como, se houve algum tipo de impacto financeiro nos negócios da empresa. Ademais a análise leva em conta ainda se a estratégia da empresa de fusão com outras empresas do setor, como por exemplo, a intenção de fusão com a empresa Estácio Participações S.A. divulgada no ano de 2016, trouxe resultados estatisticamente significativos. Para que os 
objetivos propostos sejam alcançados a pesquisa opta pelo uso da técnica de estudo de eventos para analisar o impacto de determinados acontecimentos sobre o preço das ações da empresa selecionada para o estudo.

Justifica-se, portanto, a realização desta pesquisa levando-se em conta que ela trará à luz como foi o desempenho das ações da empresa Kroton Educacional S.A. diante de vários fatos relevantes que podem ter impactado os resultados contábeis e financeiros da empresa, bem como, se a estratégia de fusão foi uma ação de gestão eficaz para manter o negócio atrativo e rentável diante da crise vivida pelo país.

\section{REVISÃO TEÓRICA}

\section{Crises, estratégias, informações relevantes e retorno das ações}

Apresenta uma breve abordagem acerca de temas relacionados ao reflexo das crises no comércio e finanças do país, no mercado de ativos, desemprego e dívida pública dos governos; estratégias, informações relevantes e o retorno das ações; e da técnica de estudos de eventos. Peksen et al. (2015) estudou as sanções políticas durante as crises e concluíram que elas prejudicam a estabilidade econômica, afetando diretamente o comércio e as finanças do país.

Reinhart et al. (2009) definiu que existem três situações que ocorrem em crises financeiras, sendo: o colapso do mercado de ativos é profundo e prolongado; os resultados de crises bancárias estão associados às saídas de recursos e desemprego; e as dívidas do governo tendem a aumentar, porém os valores em dinheiro investidos nas instituições financeiras para melhorar a liquidez não são a causa efetiva, mas sim as diminuições das taxas de receitas.

A alocação de recursos numa empresa é, fundamentalmente, influenciada pela qualidade das informações continuamente divulgadas sobre a empresa, setor e comportamento dos fundamentos de mercado, como por exemplo, inflação, taxa de juros, nível de atividade econômica, taxa de desemprego, taxa cambial etc.

Diante da exposição à ocorrência de eventos sistêmicos adversos, espera-se que as empresas desenvolvam estratégias comerciais e financeiras que atendam às expectativas dos supridores de capital. Uma empresa demonstra apresentar uma consistência estratégica quando há um equilíbrio na alocação de recursos nas empresas, ou seja, um equilíbrio entre as escolhas estratégicas nos negócios e os níveis funcionais das estratégias escolhidas (HARRISON et al., 1993). A consistência estratégica de uma empresa é considerada de alto nível quando sinaliza a existência de uma estratégia competitiva forte, ou que possa, simplesmente, ser caracterizada como sendo de inércia estrutural (PORTER, 1992).

Assim, a longevidade das empresas é consequência das estratégias adotadas pelas organizações (BURGELMAN et al., 2007). Para Collins et al. (1995) as empresas cinquentenárias já enfrentaram diversas crises políticas e econômicas e, em razão de aspectos como o estágio de maturidade do negócio, da posição de destaque no setor de atuação e do dinamismo de gestão, elas conseguiram lograr êxito em superar tais adversidades e permanecer no mercado, melhorando, inclusive, a partir de posições estratégicas consolidadas, seu desempenho econômico-financeiro. 
Como as crises são consideradas eventos dinâmicos, ou seja, não acontecem de um dia para o outro, é indispensável verificar se as estratégias adotadas pelas empresas estão dando sustentação à manutenção de resultados financeiros favoráveis. No mercado de crédito, isto contribui para a redução do custo de financiamentos de capital de giro e de imobilizações. No ambiente de bolsas de valores, espera-se que a relação entre estratégias eficazes e situação financeira positiva contribua para o aumento do retorno das ações das empresas.

Segundo Brigham et al. (2016), os acionistas são os proprietários das sociedades anônimas e compram ações porque desejam obter um bom retorno sobre seus investimentos sem exposição a riscos. As variações de preços das ações ocorrem por diversos fatores, mas existe um em particular definido por Fama (1970) como a hipótese de mercado eficiente, segundo a qual as ações refletem totalmente a avaliação das informações obtidas pelos investidores no mercado.

Neste sentido, as formas de eficiência de mercados podem ser classificadas em três grupos, sendo: forma fraca de eficiência, quando os agentes incorporam completamente as informações sobre os preços passados, ou seja, as informações históricas disponíveis publicamente são refletidas nos preços das ações; forma semiforte de eficiência, quando os preços refletem o comportamento histórico dos preços, assim como toda a informação pública disponível, tais como balanços patrimoniais, notícias, notas da diretoria etc.; e forma forte de eficiência, quando todas as informações, tanto públicas quanto privilegiadas estão refletidas nos preços das ações (FAMA,1970).

\section{Estudo de Eventos}

Os primeiros estudos feitos com eventos foram realizados por Ball et al. (1968) e comprovaram que cerca da metade da variabilidade do nível dos ganhos de lucro por ação estariam associados a efeitos econômicos. De acordo com Lyra et al. (2007), o estudo de evento tem sido utilizado em finanças para avaliar o impacto de determinado acontecimento sobre o preço das ações. A essência dos estudos de eventos é mensurar impactos nos preços de títulos em função de eventos específicos.

Mackinlay (1997) fez vários estudos sobre eventos e explica que existem muitas aplicações deste tipo de pesquisa em diversos campos, inclusive contabilidade e finanças como, por exemplo: fusões, aquisições, anúncios de resultados, emissão de novas dívidas, entre outras. Autores como Melo et al. (2015) analisou os eventos ocorridos nas ações de 54 empresas que distribuíram proventos e não realizaram a divulgação da notícia do pagamento, concluindo que não houve relevância estatística, contradizendo, portanto, o pressuposto da hipótese de mercado eficiente.

Por outro lado, Nardy et al. (2015) analisou a ocorrência de retornos e volumes anormais para as ações adicionadas ao Ibovespa entre o período de 2004 a 2013 e encontraram retornos anormais positivos próximos aos dias que antecederam a data de efetivação do índice à nova carteira. A não persistência dos retornos anormais ao longo da janela de entrada é coerente com a hipótese de pressão de preços e pode ser considerada coerente com a forma de eficiência semiforte de mercado (NARDY et al., 2015). Por fim, Sarlo 
Neto et al. (2005) afirmou que as informações divulgadas pela contabilidade devem exercer influências variadas sobre as expectativas dos investidores dependendo do tipo de ação que ele possua.

De acordo com Campbell et al. (1997) e Mackinlay (1997), as etapas que compõem um estudo de eventos podem ser descritas como sendo as seguintes: definição do evento; critério de seleção; medição de retorno normal e anormal; procedimentos de estimativas; procedimentos de testes; resultados empíricos; e interpretação.

Mackinlay (1997) define que a linha do tempo para um estudo de evento típico é em tempo do evento, ou seja: intervalo $T_{0}-T_{1}$ é o período de estimação; o intervalo $T_{1}-T_{2}$ é a janela do evento; tempo ( $\left.t_{0}\right)$ é a data do evento na hora do calendário; e intervalo $T_{2}-T_{3}$ é a janela pós-evento. Para Mackinlay (1997), muitas vezes há uma diferença entre os períodos de estimação e de eventos. A figura 1 representa cada um dos intervalos mencionados.

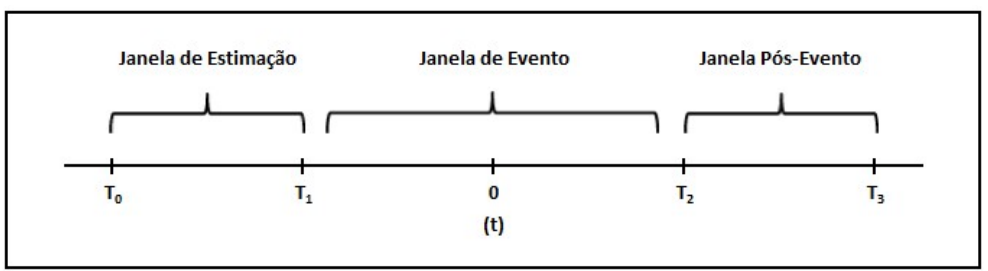

Figura 1: Janelas do Estudo de Eventos. Fonte: Campbell et al. (1997).

Onde: $t=0$ : data do evento; $t=T_{1}+1$ até $t=T_{2}$ : janela de evento; e $t=T_{0}+1$ até $t=T_{1}$ : janela de estimação. O retorno anormal será dado pelo retorno real obtido pelo título $\mathrm{R}_{\mathrm{i}, \mathrm{t}}$ subtraído do retorno normal esperado $E\left(R_{i, t}\right)$, dado $X_{t}$, que é a informação condicionante para o modelo. Para uma ação $i$, em uma data $t$, pode se estimar o retorno anormal previamente, por $A R_{i, t}=R_{i, t}-E\left[R_{i} \mid X_{t}\right]$, sendo: $A R_{i, t}$ : retorno anormal do ativo $i$ na data $t ; \mathrm{R}_{\mathrm{i}, \mathrm{t}}$ : retorno real do ativo $i$ na data $t ; \mathrm{E}\left[\mathrm{R}_{\mathrm{i}} \mid \mathrm{X}_{\mathrm{t}}\right]$ : retorno estimado do ativo $i$ na data $t$, dado o retorno de $X_{t}$. Na seção seguinte sobre a Metodologia e os procedimentos da pesquisa, serão abordados aspectos como a empresa objeto da análise, os procedimentos da pesquisa e as hipóteses formuladas.

\section{METODOLOGIA}

\section{Breve apresentação da Kroton Educacional S.A.}

Nesta seção dedicada à Metodologia e aos procedimentos da pesquisa, realiza-se uma breve apresentação da empresa objeto de estudo, definem-se as hipóteses da pesquisa e são detalhados os procedimentos adotados para a utilização do teste de estudo de eventos. A Kroton Educacional S.A. trata se de uma das maiores organizações educacionais privadas do Brasil e do mundo, com uma trajetória de mais de 45 anos de atividade na prestação de serviços de educação no ensino básico e de mais de 10 anos no ensino superior, a companhia marca presença em todos os estados do Brasil.

Dados apresentados pela Revista ISTOÉ (2016) apontam para um valor de mercado de aproximadamente US\$5,856mi, estando a frente de outras empresas de educação. A tabela 1 apresenta o valor de mercado de algumas das principais empresas de educação do mundo. A Kroton Educacional S.A. é uma empresa conhecida pela agressiva estratégia de aquisições de outras empresas do setor, a qual a elevou 
a um status de "gigante" do setor educacional. A tabela 2 apresenta algumas das principais operações de aquisições realizadas pela empresa nos últimos anos.

Tabela 1: Valor de Mercado das principais empresas de educação do mundo.

\begin{tabular}{|c|c|c|}
\hline Empresa & País & Valor de Mercado em US\$ milhões \\
\hline Kroton Anhanguera & Brasil & 5,856 \\
\hline New Oriental & China & 2,889 \\
\hline Estácio & Brasil & 2,125 \\
\hline DeVry & EUA & 2,073 \\
\hline Apollo Group & EUA & 1,956 \\
\hline
\end{tabular}

Fonte: Revista ISTOÉ (2016).

Tabela 2: Algumas das operações de aquisições realizadas pela Kroton Educacional S.A.

\begin{tabular}{|c|c|c|}
\hline Mês da aquisição & Instituição envolvida na transação & $\begin{array}{c}\text { Valor da operação em } \\
\text { Reais (R\$) }\end{array}$ \\
\hline Julho de 2011 & Centro de Ensino de Atenas Maranhense (CEAMA) & 28,4 milhões \\
\hline Setembro de 2011 & Faculdade de Sorriso Mato Grosso do Sul (FAIS) & 7,0 milhões \\
\hline Dezembro de 2011 & Universidade do Norte do Paraná (UNOPAR) & 1,3 bilhões \\
\hline Maio de 2012 & Grupo Uniasselvi & 510 milhões \\
\hline Agosto de 2012 & União Educacional Unirondom (UNIRONDOM) & 22 milhões \\
\hline
\end{tabular}

Fonte: Revista InfoMoney (2013).

Com as operações de aquisições mencionadas e o FIES facilitado no ano de 2012, a empresa apresentou uma alta de 151,5\% no desempenho de suas ações negociadas naquele ano na antiga BM\&FBovespa - atualmente B3 Brasil Bolsa Balcão (REVISTA INFOMONEY, 2013). Ademais, até o ano de 2014 a empresa manteve um ritmo acelerado de crescimento com novas aquisições e outras estratégias. A tabela 3 a seguir apresenta os principais números da Kroton Educacional S.A. no ano de 2015.

Tabela 3: Kroton Educacional S.A. em números.

\begin{tabular}{|l|c|}
\hline \multicolumn{1}{|c|}{ Descrição } & Quantidade \\
\hline Alunos de ensino superior e pós-graduação & $1.011 \mathrm{mil}$ \\
\hline Polos EAD distribuídos por todos os estados do Brasil & 910 polos \\
\hline Campi localizados em todas as regiões do país & $113 \mathrm{campi}$ \\
\hline Alunos no Pronatec & $6,8 \mathrm{mil}$ \\
\hline Alunos em cursos não regulados & $46 \mathrm{mil}$ \\
\hline Alunos de educação básica & $228 \mathrm{mil}$ \\
\hline Escolas parceiras & mais de 600 \\
\hline
\end{tabular}

Fonte: Kroton (2016).

No entanto, neste mesmo ano de 2015, em razão da crise econômica e do desemprego, todos os segmentos foram afetados. Além disto, outro fato impactou no desempenho financeiro das Instituições de Ensino Superior (IES). O Ministério da Educação (MEC) realizou mudanças de regras e critérios por meio da publicação de diferentes portarias, destacando-se dentre elas as Portarias Normativas n으, nำ21 e $n$ 을, as quais tiveram como principais efeitos: uma expressiva redução - e redistribuição com novos critérios - do número de novas vagas para alunos no Fundo de Financiamento Estudantil (FIES); e uma relevante alteração no fluxo de pagamentos das recompras do programa, com impacto significativo no fluxo de caixa das companhias (KROTON, 2016).

Apesar dos desafios ocorridos, o desempenho operacional da Kroton Educacional S.A. cresceu em 2015 cerca de 4\% frente a 2014. Na graduação presencial, a empresa cresceu em 3,5\% a sua base de alunos em relação ao ano anterior. Esse desempenho foi alcançado por meio de campanhas comerciais eficientes e 
também pelo lançamento de um produto de crédito privado desenvolvido de forma inteligente e responsável - o Parcelamento Especial Privado (PEP) - que além de oferecer condições atrativas ao aluno, conseguiu maximizar o desempenho operacional e financeiro da empresa (KROTON, 2016).

As estratégias de melhorias de desempenho da empresa não pararam por aí. O relatório da administração de 2015 informou que foram criadas algumas estratégias a fim de minimizar os impactos da crise, dentre elas: o aumento de eficiência no processo de abertura de turmas novas com a introdução de nova ferramenta de pesquisa operacional; ajustes nas estruturas administrativas do Corporativo e das unidades Presenciais realizadas ainda durante o primeiro semestre de 2015; e o programa de Strategic Sourcing voltado à otimização de despesas por meio da renegociação dos principais contratos com fornecedores (KROTON, 2016).

Por fim, em junho de 2016, a fim de continuar melhorando o seu desempenho, a Kroton Educacional S.A. anunciou a intenção de fusão com a Estácio de Sá, conforme ata de fato relevante que dizia que a base para tal potencial de combinação de negócios consistiria em uma operação que não envolveria pagamento em dinheiro, mas tão somente ações de emissão da Kroton Educacional S.A. (KROTON, 2016).

\section{Procedimentos adotados para a pesquisa}

A presente pesquisa de natureza empírico-analítica, exploratória e com abordagem quantitativa, utiliza-se como procedimento de pesquisa o estudo de caso. Para Yin (2005), o estudo de caso trata-se de uma investigação empírica sobre determinado fenômeno dentro de seu contexto de vida real, especialmente quando os limites entre o fenômeno e o contexto não estão claramente definidos. Ademais, o uso da técnica de estudo de eventos tem por objetivo possibilitar a identificação de efeito de um evento econômico em uma empresa (CAMPBELL et al., 1997).

Para Camargos et al. (2003) o estudo de evento é amplamente utilizado nos testes de aferição da eficiência do mercado em sua forma semiforte, por possibilitar um teste direto de eficiência. Isto se deve ao fato de que os retornos anormais de títulos estatisticamente iguais a zero que persistem após um tipo particular de evento são consistentes com a hipótese de que os preços se ajustam rapidamente às novas informações.

Diante disto, a presente pesquisa tem por objetivo avaliar o desempenho das ações da Kroton Educacional S.A. em decorrência de eventos ocorridos entre os anos de 2014 e 2015 que estão relacionados a eventos sistêmicos, tais como a crise econômica do país, a perda de postos de trabalho pela população economicamente ativa, alterações nos critérios de concessão do Fundo de Financiamento Estudantil (FIES) e a eventos de estratégia empregada pela empresa como, por exemplo, as operações de fusão com outras empresas, especificamente a divulgação de intenção de fusão anunciada com a Estácio Participações S.A. Para tal, são formuladas as seguintes hipóteses:

Ho (Hipótese Nula): Os retornos das ações ordinárias da Kroton Educacional S.A. não são afetados por eventos sistêmicos e eventos de estratégia empregados pela empresa;

H$_{1}$ (Hipótese Alternativa 1): A crise de 2015, após a divulgação dos resultados anuais da Kroton Educacional S.A. afetou de forma estatisticamente significativa, os retornos das ações ordinárias da empresa; 
$\mathrm{H}_{2}$ (Hipótese Alternativa 2): As alterações impostas pela Portaria Normativa no 21 de 2014, afetaram de forma estatisticamente significativa, os retornos das ações ordinárias da Kroton Educacional S.A.;

$\mathrm{H}_{3}$ (Hipótese Alternativa 3): A divulgação de intenção de fusão com a Estácio Participações S.A. em 02.06.2016 afetou, de forma estatisticamente significativa, os retornos das ações ordinárias da Kroton Educacional S.A.;

$\mathrm{H}_{4}$ (Hipótese Alternativa 4): A reportagem da Revista Veja de 21.01.2017 intitulada "FIES: um pesadelo para os alunos e uma farra para as universidades", afetou, de forma estatisticamente significativa, os retornos das ações ordinárias da Kroton Educacional S.A.

Para que as hipóteses formuladas possam ser testadas, foram extraídos os valores de cotação das ações da empresa do banco de dados Economática, sendo a seleção dos eventos feita a partir da divulgação de notícias por meio da mídia e de órgãos reguladores. Assim, foram selecionados os seguintes eventos: divulgação pela Kroton Educacional S.A. de intenção de fusão com a Estácio Participações S.A. em 02.06.2016; alterações nas regras do Fundo de Financiamento Estudantil (FIES) pelas Portarias Normativas no 21 e no 23 de 2014 emitidas pelo Fundo Nacional de Desenvolvimento da Educação (FNDE); divulgação dos resultados anuais de 2015 na data de 15.03.2016 em meio à crise econômica nacional; e publicação de reportagem pela Revista Veja em 21.01.2017 acerca dos problemas do programa FIES.

Para medição do retorno normal e retorno anormal, bem como os procedimentos de estimativas, utilizou-se uma janela de eventos de 4 dias antes $\left(D_{-4}\right)$ até 4 dias depois $\left(D_{+4}\right)$, ao redor da data do evento $\left(D_{0}\right)$, com uma janela de estimação de 40 dias ( $D_{-5}$ a $D_{-44}$ ) para cálculo do beta a partir do método dos mínimos quadrados. Estimou-se a partir daí os retornos anormais (AR), também conhecidos como abnormal return, e os retornos anormais acumulados (CAR), também denominados de cumulative abnormal return. $\mathrm{O}$ retorno anormal é calculado a partir do modelo de mercado, ou método dos mínimos quadrados (MACKINLAY, 1997): $\mathrm{R}_{\mathrm{it}}=\alpha_{\mathrm{i}}+\beta_{\mathrm{i}} \times \mathrm{Rm}_{\mathrm{t}}+\varepsilon_{\mathrm{it}} ; \mathrm{E}\left(\varepsilon_{\mathrm{it}}\right)=0 ; \operatorname{var}\left(\varepsilon_{\mathrm{it}}\right)=\sigma_{\varepsilon i t}^{2} \mathrm{t}$, onde: $\mathrm{R}_{\mathrm{it}}$ trata-se dos retornos no período $t$ do título $i ; \mathrm{Rm}_{\mathrm{t}}$ refere-se aos retornos no período $t$ da carteira de mercado; $\varepsilon_{i t}$ é o ruído branco; e $\alpha_{i}, \beta_{i}, \sigma^{2}, \varepsilon_{i t}$ são os itens a estimar do modelo.

Os valores do Ibovespa foram utilizados para o cálculo da carteira de mercado e os retornos foram calculados de forma logarítmica para estimar $\alpha$ e $\beta$, diariamente por 40 dias. Assim, temos as seguintes equações: $R_{i t}=\ln \left(R_{i, t} \div R_{i, t-1}\right)$ e $R m_{t}=\ln \left(R m_{t} \div R m_{t-1}\right)$. A diferença entre o retorno obtido e o retorno do mercado é o retorno anormal (AR), dado pela equação anterior. Tem-se, agora, $R A_{i t}=R_{i t}-\left(\alpha_{i}+\beta_{i} \times R m_{t}\right)$, onde: $\mathrm{RA}_{\mathrm{it}}$ trata-se do retorno anormal de $i$ para o período $t ; \mathrm{R}_{\mathrm{it}}$ refere-se ao retorno em $t$ do título $i ; \mathrm{Rm}_{\mathrm{t}}$ é o retorno da carteira de mercado em $t$; e $\alpha_{i}$ e $\beta_{i}$ são os parâmetros estimados pelo modelo. Portanto, o retorno anormal acumulado $(C A R)$ é dado por: $C A R=\mathbb{E}_{i}^{t} R A$, onde: $C A R$ trata-se do retorno anormal acumulado e $t, i$ refere-se ao intervalo da janela estudada.

Como procedimento de teste foi empregado o teste $t$ de student para verificar a significância do retorno acumulado, sendo que, possui significância estatística $p$-values inferiores a $5 \%$, pois demonstram que o evento foi preponderante para explicar o comportamento do retorno da ação. Na seção seguinte deste artigo são efetuadas as análises de dados e apresentados os resultados obtidos pela pesquisa. 


\section{Análise de dados}

A seção de análise de dados está subdividida em 4 subseções, sendo: análise das alterações nas regras do FIES pelas Portarias Normativas n-21 e n23 de 2014 emitidas pelo Fundo Nacional de Desenvolvimento da Educação (FNDE); divulgação dos resultados anuais referentes ao exercício social de 2015 ocorrido em 15.03.2016; divulgação de intenção de fusão com a Estácio Participações S.A. em 02.06.2016; e publicação de reportagem pela Revista Veja em 21.01.2017 sobre problemas do programa FIES.

\section{Análises das alterações nas regras do FIES sobre o retorno das ações ordinárias}

A tabela 4 apresenta o cálculo do retorno anormal (AR) e retorno anormal acumulado (CAR) para verificar a influência das alterações nas regras do FIES pelas Portarias Normativas já mencionadas sobre o retorno das ações ordinárias da Kroton Educacional S.A.. Contrariamente, a predominância de p-values sinaliza que o retorno das ações ordinárias da Kroton Educacional S.A. não foi afetado, de forma estatisticamente significativa, pelas alterações nas regras do FIES. Trata-se, todavia, de análise estática, não representando necessariamente a verdadeira reação do mercado investidor. Em parte, esse comentário está embasado na ocorrência de $p$-values inferiores a $5 \%$, o que sugeriria que o mercado, na eminência da aprovação das regras do FIES, tenha ajustado antecipadamente o preço das ações ordinárias, conforme observado na janela D-4.

Tabela 4: Cálculo do retorno anormal (AR) e retorno anormal acumulado (CAR).

\begin{tabular}{|r|r|r|r|r|r|}
\hline Data & Janela & \multicolumn{1}{c|}{ AR } & \multicolumn{1}{c|}{ CAR } & \multicolumn{1}{c|}{$\boldsymbol{p}$-value } \\
\hline 21.12 .2015 & D-4 & 0,0509 & 0,0509 & 1,8354 & $\mathbf{0 , 0 3 3 2}$ \\
\hline 22.12 .2015 & D-3 & $-0,0189$ & 0,0320 & 0,8185 & 0,2065 \\
\hline 23.12 .2015 & D-2 & $-0,0279$ & 0,0041 & 0,0853 & 0,4660 \\
\hline 28.12 .2015 & D-1 & 0,0124 & 0,0164 & 0,2976 & 0,3830 \\
\hline 29.12 .2015 & D0 & 0,0077 & 0,0242 & 0,3920 & 0,3475 \\
\hline 30.12 .2015 & D+1 & $-0,0310$ & $-0,0068$ & $-0,1014$ & 0,5404 \\
\hline 04.01 .2016 & D+2 & 0,0280 & 0,0211 & 0,2888 & 0,3864 \\
\hline 05.01 .2016 & D+3 & $-0,0340$ & $-0,0128$ & $-0,1641$ & 0,5652 \\
\hline 06.01 .2016 & D+4 & 0,0394 & 0,0265 & 0,3199 & 0,3745 \\
\hline
\end{tabular}

\section{Análises da divulgação dos resultados anuais de 2015 sobre o retorno das ações ordinárias}

A Tabela 5 apresenta o cálculo do retorno anormal (AR) e retorno anormal acumulado (CAR) para verificar a influência da divulgação dos resultados anuais de 2015 ocorrido em 15.03.2016 sobre o retorno das ações ordinárias da Kroton Educacional S.A. Contrariamente, a predominância de $p$-values sinaliza que o retorno das ações ordinárias da Kroton Educacional S.A. não foi afetado, de forma estatisticamente significativa, pela divulgação dos resultados contábeis anuais de 2015 em meio à crise econômica nacional. Trata-se, todavia, de análise estática, não representando necessariamente a verdadeira reação do mercado investidor. Em parte, esse comentário está embasado na ocorrência de CAR negativos a partir de D-1, o que sugeriria a confirmação das expectativas dos investidores, já evidenciada pela piora dos resultados da empresa antecipada pelos balancetes trimestrais ao longo do exercício social de 2015. 
Tabela 5: Cálculo do retorno anormal (AR) e retorno anormal acumulado (CAR).

\begin{tabular}{|r|r|r|r|r|r|}
\hline Data & \multicolumn{1}{|c|}{ Janela } & \multicolumn{1}{c|}{ AR } & \multicolumn{1}{c|}{ CAR } & \multicolumn{1}{c|}{$\boldsymbol{p}$} & $\boldsymbol{p}$-value \\
\hline 09.03 .2016 & D-4 & 0,0144 & 0,0144 & 0,5094 & 0,3052 \\
\hline 10.03 .2016 & D-3 & 0,0049 & 0,0193 & 0,4827 & 0,3147 \\
\hline 11.03 .2016 & D-2 & 0,0062 & 0,0255 & 0,5204 & 0,3014 \\
\hline 14.03 .2016 & D-1 & $-0,0284$ & $-0,0029$ & $-0,0513$ & 0,5205 \\
\hline 15.03 .2016 & D0 & 0,0013 & $-0,0016$ & $-0,0247$ & 0,5099 \\
\hline 16.03 .2016 & D+1 & $-0,0353$ & $-0,0368$ & $-0,5277$ & 0,7012 \\
\hline 17.03 .2016 & D+2 & $-0,0274$ & $-0,0643$ & $-0,8426$ & 0,8003 \\
\hline 18.03 .2016 & D+3 & 0,0034 & $-0,0609$ & $-0,7486$ & 0,7730 \\
\hline 21.03 .2016 & D+4 & $-0,0134$ & $-0,0743$ & $-0,8632$ & 0,8060 \\
\hline
\end{tabular}

\section{Análises da divulgação de intenção de fusão com a Estácio Participações S.A.}

A tabela 6 apresenta o cálculo do retorno anormal (AR) e retorno anormal acumulado (CAR) para verificar a influência da divulgação de intenção de fusão com a Estácio Participações S.A. ocorrida em 02.06.2016 sobre o retorno das ações ordinárias da Kroton Educacional S.A. Pela tabela 6 verifica-se a ocorrência de $p$-values inferiores a 5\%, o que demonstra que a divulgação de interesse da Kroton Educacional S.A. em realizar operação de fusão com a Estácio Participações S.A. teve efeitos estatísticos positivamente significativos nos retornos dos valores das ações ordinárias da Kroton Educacional S.A. entre as janelas D0 até $\mathrm{D}+4$. Diante disso, a Hipótese Alternativa $\left(\mathrm{H}_{3}\right)$ foi confirmada, oferecendo indícios de reação do mercado na forma de eficiência semiforte, uma vez que os preços das ações negociadas no mercado reagiram à informação recebida e disponível ao público em geral.

Tabela 6: Cálculo do retorno anormal (AR) e retorno anormal acumulado (CAR).

\begin{tabular}{|r|r|r|r|r|r|}
\hline Data & Janela & \multicolumn{1}{c|}{ AR } & \multicolumn{1}{c|}{ CAR } & \multicolumn{1}{c|}{$\boldsymbol{T}$} & $\boldsymbol{p}$-value \\
\hline 27.05 .2016 & D-4 & 0,0154 & 0,0154 & 0,7295 & 0,2329 \\
\hline 30.05 .2016 & D-3 & $-0,0010$ & 0,0144 & 0,4835 & 0,3144 \\
\hline 31.05 .2016 & D-2 & 0,0240 & 0,0384 & 1,0513 & 0,1466 \\
\hline 01.06 .2016 & D-1 & 0,0001 & 0,0385 & 0,9126 & 0,1807 \\
\hline 02.06 .2016 & D0 & 0,1088 & 0,1473 & 3,1162 & $\mathbf{0 , 0 0 0 9}$ \\
\hline 03.06 .2016 & D+1 & 0,0043 & 0,1517 & 2,9262 & $\mathbf{0 , 0 0 1 7}$ \\
\hline 06.06 .2016 & D+2 & $-0,0181$ & 0,1336 & 2,3883 & $\mathbf{0 , 0 0 8 5}$ \\
\hline 07.06 .2016 & D+3 & 0,0105 & 0,1441 & 2,4114 & $\mathbf{0 , 0 0 7 9}$ \\
\hline 08.06 .2016 & D+4 & 0,0150 & 0,1591 & 2,5058 & $\mathbf{0 , 0 0 6 1}$ \\
\hline
\end{tabular}

\section{Análises da publicação de reportagem pela Revista Veja sobre problemas do programa FIES}

A tabela 7 apresenta o cálculo do retorno anormal (AR) e retorno anormal acumulado (CAR) para verificar a influência da publicação de reportagem pela Revista Veja ocorrida em 23.01.2017 sobre o retorno das ações ordinárias da Kroton Educacional S.A. Contrariamente, a predominância de $p$-values sinaliza que o retorno das ações ordinárias da Kroton Educacional S.A. não foi afetado, de forma estatisticamente significativa, pela publicação da reportagem da Revista Veja em 23.01.2017 acerca dos problemas apresentados pelo Programa FIES. Trata-se, todavia, de análise estática, não representando necessariamente a verdadeira reação do mercado investidor. Em parte, esse comentário está embasado na ocorrência CAR negativos a partir de D-1, porém nota-se que o mercado absorve a informação e logo após retorna a sua normalidade. 
Tabela 7: Cálculo do retorno anormal (AR) e retorno anormal acumulado (CAR).

\begin{tabular}{|r|r|r|r|r|r|}
\hline Data & \multicolumn{1}{|c|}{ Janela } & \multicolumn{1}{c|}{ AR } & \multicolumn{1}{c|}{ CAR } & \multicolumn{1}{c|}{$\boldsymbol{T}$} & \multicolumn{1}{c|}{$\boldsymbol{p}$-value } \\
\hline 17.01 .2017 & D-4 & 0,0300 & 0,0300 & 1,2850 & 0,09939 \\
\hline 18.01 .2017 & D-3 & $-0,0201$ & 0,0099 & 0,3001 & 0,38204 \\
\hline 19.01 .2017 & D-2 & $-0,0109$ & $-0,0010$ & $-0,0243$ & 0,50971 \\
\hline 20.01 .2017 & D-1 & $-0,0014$ & $-0,0024$ & $-0,0512$ & 0,52041 \\
\hline 23.01 .2017 & D0 & $-0,0699$ & $-0,0723$ & $-1,3820$ & 0,91651 \\
\hline 24.01 .2017 & D+1 & 0,0275 & $-0,0449$ & $-0,7832$ & 0,78325 \\
\hline 25.01 .2017 & D+2 & 0,0026 & $-0,0422$ & $-0,6827$ & 0,75261 \\
\hline 26.01 .2017 & D+3 & 0,0592 & 0,0170 & 0,2555 & 0,39917 \\
\hline 27.01 .2017 & D+4 & $-0,0339$ & $-0,0169$ & $-0,2404$ & 0,59499 \\
\hline
\end{tabular}

\section{CONSIDERAÇÕES FINAIS}

O presente trabalho buscou verificar impactos estatísticos significativos no retorno das ações ordinárias da Kroton Educacional S.A. (KROT3). Em termos gerais, para dois dos quatro eventos analisados os resultados indicaram a presença de retornos anormais significativos estatisticamente que corroboraram com a hipótese de eficiência de mercado na forma semiforte.

Os indícios apresentados por meio de testes estatísticos demonstraram haver uma reação positiva do mercado ao anúncio de intenção de fusão com a Estácio Participações S.A., o que demonstra que a estratégia da companhia em buscar empresas para realizar fusões e aquisições traz retornos positivos para o valor das suas ações. Já no caso das alterações nas regras do FIES, os retornos anormais observados foram antes da data de divulgação dos fatos relevantes, o que pode ter acontecido em função de vazamento de informações antecipadas para os agentes antes da divulgação das Portarias Normativas emitidas pelo Fundo Nacional de Desenvolvimento da Educação (FNDE) que alteraram o regulamento do programa.

Outro fator relevante para não se ter retornos anormais acumulados em todas as janelas seriam os programas de parcelamentos privados que a Kroton Educacional S.A. oferece para manutenção da carteira de alunos. Com relação à divulgação dos resultados de 2015, a predominância de $p$-values sinaliza que o retorno das ações ordinárias da Kroton Educacional S.A. não foi afetado, de forma estatisticamente significativa pela divulgação dos resultados contábeis anuais de 2015 em meio à crise econômica nacional.

Trata-se, todavia, de análise estática, não representando necessariamente a verdadeira reação do mercado investidor. Em parte, esse comentário está embasado na ocorrência de CAR negativos a partir de D-1, o que sugere a confirmação das expectativas dos investidores, já evidenciada pela piora dos resultados da empresa nos balancetes trimestrais antecipados ao longo de 2015. Como recomendação para estudos futuros, sugere-se a análise de outras empresas que adotaram estratégias para melhorar seu desempenho e de situações críticas que antecederam essas estratégias, a fim de verificar se estes eventos ocasionaram efeitos positivos ou negativos sobre os retornos das ações.

\section{REFERÊNCIAS}

BALL, R.; BROWN, P.. An empirical evaluation of accounting numbers. Journal of Accounting Research, Chicago, v.6, n.6, p.159-178, 1968.

BRIGHAM E. F.; EHRHARDT, M. C.. Administração Financeira: teoria e prática. 3 ed. São Paulo: Cengage Learning, 2016.
BURGELMAN, R. A.; GROVE, A. S.. Let chaos reign, then rein in chaos - repeatedly: managing strategic dynamics for corporate longevity. Strategic Management Journal, v.28, n.10, p.965-979, 2007. 
CAMARGOS, M. A.; BARBOSA, F. V.. Estudos de evento: teoria e operacionalização. Caderno de Pesquisas em Administração, v.10, n.3, p.1-20, 2003.

CAMPBELL, J. Y.; LO, A. W. A.; MACKINLAY, C.. The econometric of financial markets. Princeton, New Jersey: Princeton University Press, 1997.

COLLINS, J. C.; PORRAS, J. I.. Feitas para durar: práticas bemsucedidas de empresas visionárias. Rio de Janeiro: Rocco, 1995.

FAMA, E. F.. Efficient capital markets: a review of theory and empirical work. The Journal of Finance, Chicago, v.5, n.2, 1970.

FNDE. Fundo Nacional de Desenvolvimento da Educação. Portaria Normativa n.21 de 26 de dezembro de 2014. Bbrasíçia: FNDE, 2014.

HARRISON, J. S.; HALL, E. H.; NARGUNDAKAR, R.. Resource allocation as an outcropping of strategic consistency: Performance implications. Academy of Management Journal, v.36, n.5, p.1026-1051, 1993.

IBGE. Instituto Brasileiro de Geografia e Estatística. Indicadores IBGE: Pesquisa Nacional por Amostra de Domicílios Contínua. Rio de Janeiro: IBGE, 2017.

KROTON. Kroton Educacional S.A.. Fatos relevantes 2016: Demonstrações Financeiras (ITR / DFP). Belo Horizonte: Kroton Educacional S.A., 2016.

LYRA, R. L. W. C.; TOLEDO FILHO J. R.; OLINQUEVITCH, J. L.. Análise do conteúdo informacional dos investimentos em ativos imobilizados: um estudo de eventos em empresas negociadas na Bovespa. Revista Universo Contábil, v.3, n.2, p.39-54, 2007.
MACKINLAY, A. C. Event studies in economics and finance. Journal of Economic Literature, Nashville, v.35, n.1, p.13-39, 1997.

MELO, F. J.; FONSECA, M. W.. Política de Dividendos no Brasil: Uma análise na reação do mercado a anúncio de distribuição de proventos. Revista Contemporânea de Contabilidade, v.12, n.27, p.137-164, 2015.

NARDY, A.; FAMÁ, R.; GUEVARA, J. A. H.; MUSSA, A.. A verificação da ocorrência do efeito índice no lbovespa 2004-2013. Revista de Administração, v.50, n.2, p.153-168, 2015.

PEKSEN, D.; SON, B.. Economic coercion and currency crises in target countries. Journal of Peace Research, v.52, n.4, p.448-462, 2015.

PORTER, M. E.. Vantagem competitiva. 3 ed. Rio de Janeiro: Campus, 1992.

REINHART, C.; ROGOFF, K.. The aftermath of financial crises. National Bureau of Economic Research, v.7, n.3, 2009.

REVISTA INFOMONEY. As 6 aquisições que tornaram a Kroton a maior empresa de educação do mundo. Rio de Janeiro: InfoMoney, 2013.

REVISTA ISTOÉ. Gigantes de Educação: Edição no2267 de 01.05.2013. São Paulo: IstoÉ, 2016.

SARLO NETO, A.; TEIXEIRA, A. J. C.; LOSS, L.; LOPES, A. B.. O diferencial no impacto dos resultados contábeis nas ações ordinárias e preferenciais no mercado brasileiro. Revista Contabilidade e Finanças, São Paulo, n.37, p.46-58, 2005.

YIN, R.. Estudo de Caso: Planejamento e Métodos. Porto Alegre: Bookman, 2005. 